\title{
An Innovative Skin Simulation Model to Augment Competency-based Training in Facial Plastic Surgery
}

\author{
Satyaswarup Tripathy ${ }^{10}$ \\ Devi Prasad Mohapatra2(1) \\ Friji Meethale Thiruvoth ${ }^{2}$ \\ Ramesh Kumar Sharma ${ }^{1}$ \\ Likhitha Reddy ${ }^{2}$ Neljo Thomas ${ }^{2}$
}

${ }^{1}$ Department of Plastic Surgery, Post Graduate Medical Education and
Research (PGIMER), Chandigarh, India
${ }^{2}$ Department of Plastic Surgery, JIPMER, Gorimedu, Puducherry, India

Address for correspondence Devi Prasad Mohapatra, MCh, Department of Plastic Surgery, 4th Floor SSB, JIPMER, Puducherry 605006, India (e-mail: devimohapatra1@gmail.com).

Indian J Plast Surg 2022;55:102-106.

\begin{abstract}
Keywords

- residents training

- CBME

- facial plastic surgery

- flaps

- surgical simulation

Introduction Competency-based medical education (CBME) approach in the medical curriculum has been introduced globally with the goal of providing flexibility, accountability, and learner-centeredness among medical learners. Traditional surgical skill training in most places has relied on "see one, do one, teach one model," while simulation model-based training has been shown to improve competencies in surgical trainees. We wanted to assess the usefulness of a hydrophilic barrier adhesive foam wound dressing as a novel skin simulation model for learning biomechanics and practice of cutaneous flaps among plastic surgical resident trainees at our institute. Materials and Methods An absorbent, soft polyurethane foam pad located centrally upon a larger polyurethane membrane, coated with a hydrocolloid adhesive, forming an island dressing, was used as a simulation model for this study. It was obtained from the hospital store either after or nearing their expiry dates of clinical use. Plastic surgery residents in different years of training were invited to participate in a simulation workshop, using this novel model, and give their feedback.

Results Seventeen residents in different plastic surgery training levels participated in the workshop and gave their feedback on the skin flap simulation model. The simulation model received extremely high $(100 \%)$ scores on two parameters, namely, utility for flap and suture practice and high scores (88\%-94\%) for texture, ability to mark, and improving confidence among trainees.

Conclusions Adhesive bilayer polyurethane foam can be used as a novel cutaneous skin flap simulation model for understanding the biomechanics of skin flaps and cutaneous flap practice.
\end{abstract}

published online

February 25, 2022
DOI https://doi.org/ $10.1055 / \mathrm{s}-0041-1740083$ ISSN 0970-0358.

\footnotetext{
(c) 2022. Association of Plastic Surgeons of India. All rights reserved This is an open access article published by Thieme under the terms of the Creative Commons Attribution-NonDerivative-NonCommercial-License, permitting copying and reproduction so long as the original work is given appropriate credit. Contents may not be used for commercial purposes, or adapted, remixed, transformed or built upon. (https://creativecommons.org/ licenses/by-nc-nd/4.0/)

Thieme Medical and Scientific Publishers Pvt. Ltd., A-12, 2nd Floor, Sector 2, Noida-201301 UP, India
} 


\section{Introduction}

Traditional surgical skill training in most places has relied on "see one, do one, teach one" model where the surgical trainee is expected to see procedural skills from an experienced practitioner, memorize the skills, replicate these when the opportunity arises, and further teach it to a new trainee who then carries the tradition forward. ${ }^{1}$ With increasing patient awareness and advocacy, ethical and legal issues have come to the fore in these training schemes. This, combined with a lack of confidence among trainees due to inadequate exposure and practice, has led to the promotion of simulationbased surgical skill training in newer surgical curricula. Cutaneous surgical procedures, including suturing techniques, biopsy techniques, and skin flap procedures, are amenable to simulation-based skill training.

\section{Aim}

We aim to assess the usefulness of a hydrophilic barrier adhesive foam wound dressing as a novel skin simulation model for learning biomechanics as well as the practice of cutaneous flaps among plastic surgical resident trainees at our institute.

\section{Materials and Methods}

An absorbent, soft polyurethane foam pad located centrally upon a larger polyurethane membrane, coated with a hydrocolloid adhesive (- Fig. 1), forming an island dressing (Biatain Adhesive), was used as a simulation model for this study. These dressing materials were obtained from the hospital store as they were nearing their expiry or were in postexpiry dates of clinical use. They were thought of as materials to be used for teaching purposes. A skin simulation model feedback sheet was designed for this study, and items were validated for content with the help of experts. It was designed to capture participant opinion on simulation model characteristics on a Likert scale. The simulation model was assessed for four characteristics parameters: texture, pliability, ability to mark, and handling with instruments. It was also evaluated for four utility parameters, namely, suture practice, flap practice, confidence improvement, and novel flap designing. The feedback scores per item and overall scores were then captured from this sheet. Trainees from the department of plastic surgery were invited to participate in a cutaneous flap workshop. After delivering an overview of
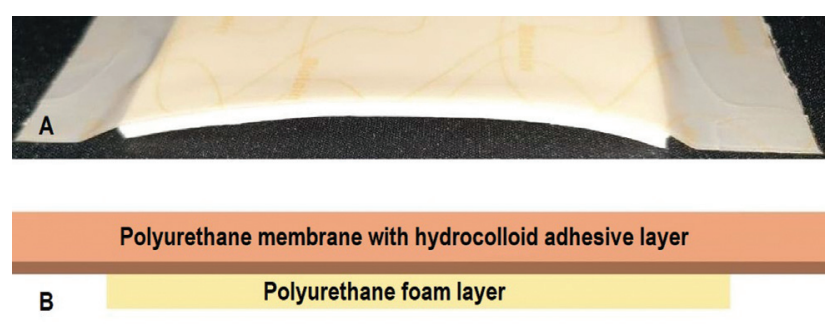

Fig. 1 Figure showing cross-section through simulation model (A) with a schematic representation (B). cutaneous flaps in practice to the participants, they were provided with a skin simulation board (created by fixing the hydrophilic barrier adhesive foam wound dressing to a rigid rubber board), skin marking pen, measuring scale, surgical instruments, and sutures (4'0 prolene). A list of activities was provided to participants to execute on the skin simulation board. Defects were created on the simulation model, and the participants were allowed to recreate skin flaps for coverage of the defects. All participants were then invited to complete the feedback form at the end of the workshop.

Demographic data of participants and feedback scores for each participant were collected from the feedback form and expressed in percentage of the total score. Item-wise scores for all participants were also collected.

\section{Results}

Seventeen plastic surgery residents in the first, second, and third year of training participated in a one-day cutaneous flap simulation workshop. They provided feedback in the skin simulation model feedback sheet. The participants performed different activities, as assigned to them in the worksheet (-Fig. 2A), including performing Z-plasties, bilobed flaps, hatchet flap, Limberg flaps, linear suturing, purse-string suturing, etc. (-Fig. 3) (-Video 1). Participant feedback scores for all parameters were captured from the feedback form (-Fig. 2B) (-Table 1). Nearly 30\% of participants responded that the simulation model did not feel similar to normal skin during instrumentation and was not useful for designing novel flaps, while $40 \%$ of residents thought it was not pliable enough. The simulation model, however, received extremely high (100\%) scores on two parameters, namely, utility for flap and suture practice, and high scores (88\%-94\%) for texture, ability to mark (-Fig. 4), and improving confidence.

\section{Video 1}

Video demonstrating the utility of skin simulation model. Online content including video sequences viewable at: https://www.thieme-connect.com/ products/ejournals/html/10.1055/s-0041-1740083.

\section{Discussion}

Simulation models have been known to improve competencies in surgical trainees. ${ }^{2}$ The Oxford dictionary has defined competency as "the ability to do something successfully and efficiently." 3 Keeping the goal of learner competence in mind, competency-based medical education (CBME) is being widely adopted across the globe as well as India. Traditional surgical training has followed Halstedian pattern of residency, which is based on timed exposure and knowledge assessment (loosely translated into on "see one, do one, teach one" model) and aided by the maintenance of operative case logs and board/university examinations., 4 
FKIN SIMULATION PRACTICE TASKS

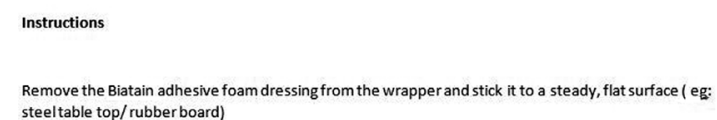
steeltable top/rubberboard)

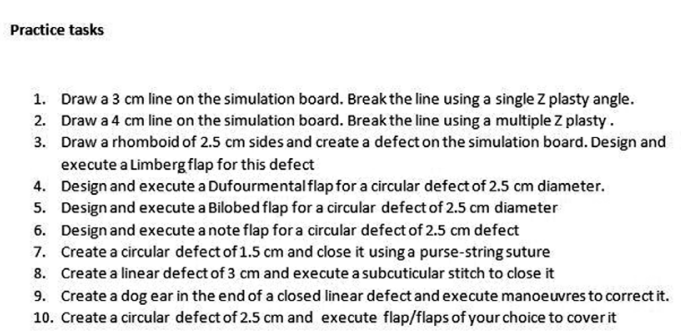

Fig. 2 Simulation practice tasks (A) and feedback form (B).

The CBME approach in the medical curriculum, which includes flexibility, accountability, and learner-centeredness, was proposed by the erstwhile Medical Council of India (MCI) to improve learners' skills. ${ }^{6}$ This approach becomes essential for surgical trainees where a time variable but competency-based learning and assessment will help trainees develop the competencies expected of them once their training is completed. Simulation models in facial plastic surgery, such as shown in this study, will help residents improve cognitive and psychomotor skills and help provide instructors an opportunity to supervise, assess closely, and guide trainee development. ${ }^{7}$

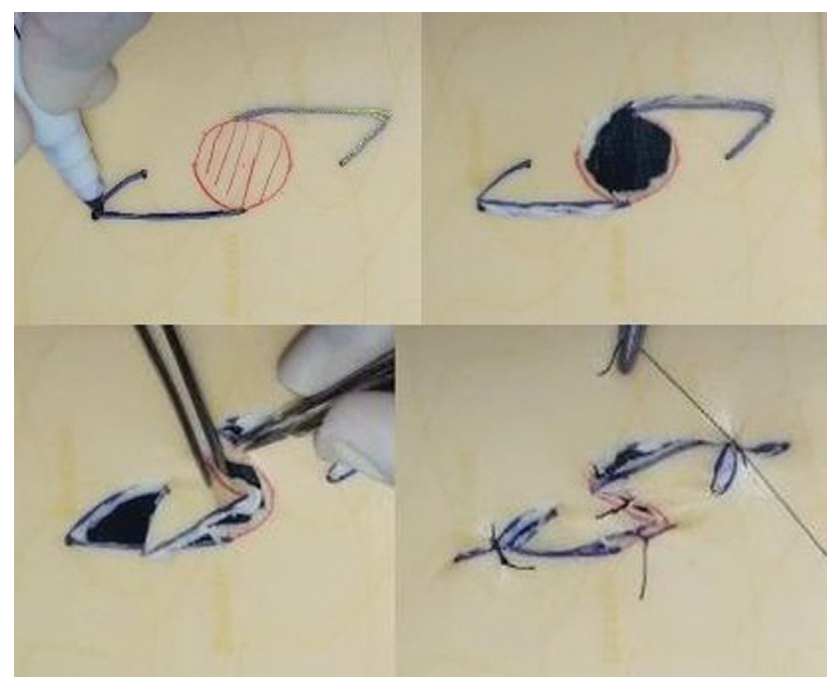

Fig. 3 Marking, designing, and execution of hatchet flap on simulation model.

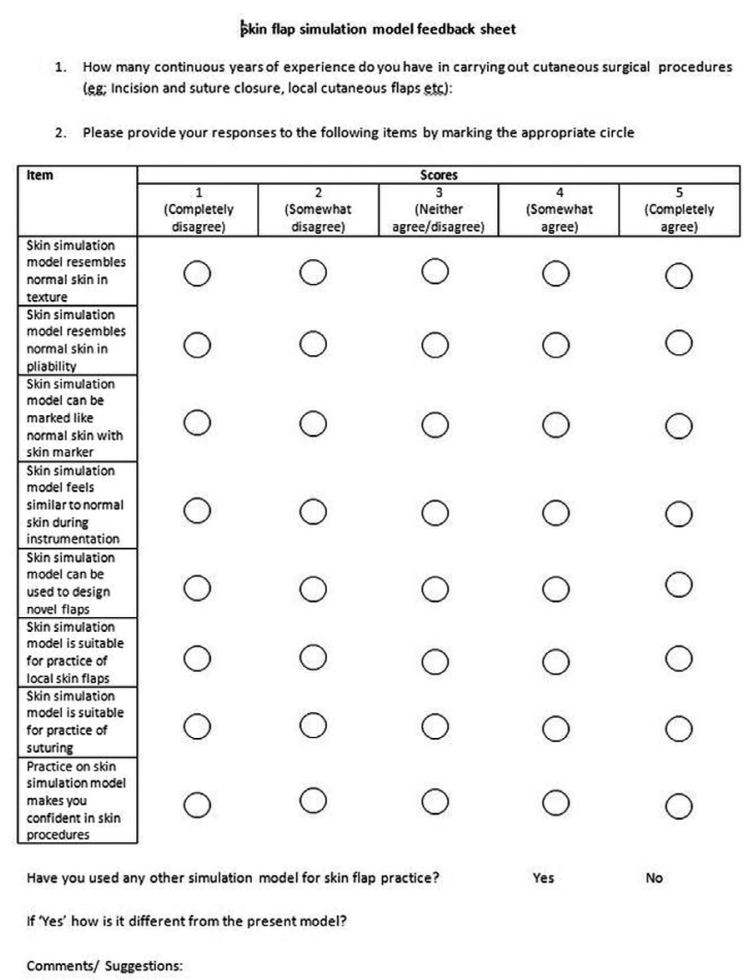

Accurate designing and execution of skin flaps are essential, particularly over the face, where the presence of important landmarks interposed with varying areas of lax and taut skin determine flap design and outcomes. An understanding of skin's biomechanical qualities, namely, normal skin tension and directional properties, extensibility and contractility of skin, and viscoelastic properties of skin, help surgeons design and execute skin flaps. ${ }^{8}$ For a senior plastic surgeon, this understanding comes from experience, while it is usually a "trial and error" for beginners. Simulation-based learning is a well-accepted active learning process. It is now integrated into undergraduate and postgraduate medical curricula worldwide. ${ }^{9}$ The use of simulation in plastic surgery training has been in practice for the last few years. ${ }^{10}$ Simulation practice of flap procedures provides trainees a relaxed learning environment, with an opportunity to practice several times and improve upon their mistakes, ultimately building up on their self-confidence. Simulationbased flap learning contributes to patient safety, autonomy, and patient ethics such as social justice. It also prepares the resident with necessary surgical and error management skills. $^{11}$

Numerous models have been adopted for cutaneous surgical skill simulation, including dry models such as siliconbased models, foam-based models, hybrid models, and wet models including banana peel, goatskin, pigskin, fresh cadaver, soft embalmed cadaver, etc. Innovative uses of discarded abdominoplasty specimens have also been described. ${ }^{12}$ An ideal skin simulation model for surgical skill practice should have the following: viscoelastic properties and color similar to normal skin, odorless, readily available, 
Table 1 Table showing feedback scores

\begin{tabular}{|l|l|l|l|}
\hline Parameters & Score (Mean \pm SD) & Score (Median $[$ IQR]) & Percentage of 4/5 score \\
\hline 1. Texture & $3.94 \pm 0.66$ & $4(0)$ & $15 / 17(88 \%)$ \\
\hline 2. Pliability & $3.23 \pm 1.20$ & $4(2)$ & $10 / 17(59 \%)$ \\
\hline 3. Markability & $4.76 \pm 0.56$ & $5(0)$ & $16 / 17(94 \%)$ \\
\hline 4. Similarity & $3.82 \pm 0.95$ & $4(1.5)$ & $12 / 17(70.58 \%)$ \\
\hline 5. Utility (novel flaps) & $4.06 \pm 1.14$ & $4(1.5)$ & $13 / 17(76.47 \%)$ \\
\hline 6. Practicality (skin flaps) & $4.56 \pm 0.50$ & $5(1)$ & $17 / 17(100 \%)$ \\
\hline 7. Practicality (suturing) & $4.82 \pm 0.39$ & $5(0)$ & $17 / 17(100 \%)$ \\
\hline 8. Utility (confidence) & $4.29 \pm 0.68$ & $4(1)$ & $15 / 17(88 \%)$ \\
\hline
\end{tabular}

Abbreviations: IQR, interquartile range; SD, standard deviation.

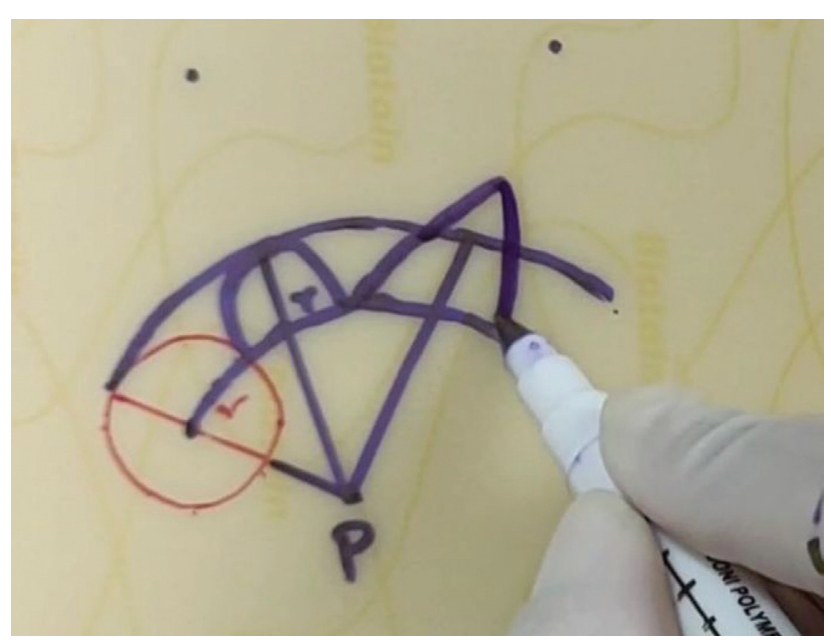

Fig. 4 Showing the excellent marking ability nature of simulation model.

should not have special storage requirements, be inexpensive, nonmessy during handling and, finally, should not involve ethical or legal issues. A review of the literature reveals that a suitable skin simulation model having the qualities mentioned above for the practice of geometrical skin flaps by learners has been restricted by availability, cost, and other issues. ${ }^{13}$ While the commercially designed simulators are expensive, indigenously designed skin models have limitations of availability and standardization. ${ }^{14,15}$

Formalin-preserved cadavers have been used traditionally for practice of skin flaps, but these are limited by their availability, need to visit cadaver dissection hall, and a pungent odor that persisted for quite some time after completion of the practice session. Formalin also causes irritation to the eyes. An accurate understanding of the biomechanics of skin flaps is restricted in formalin-preserved skin, owing to the mummification effect of formalin, which makes the skin hard and leathery. This was overcome to some extent by the introduction of soft embalmed cadavers in our institute, which is a specialized process and incurs substantial expenses. The skin textures in soft embalmed cadavers and fresh cadavers resemble natural skin and provide a surgical experience closest to natural. ${ }^{16}$ These are, however, again limited by availability and a need to visit the dissection hall. Both these techniques provide the closest anatomical experience, which is essential while designing and executing flaps in various subunits of the face where landmark distortions need to be kept into consideration. Wet skin simulation models described in the literature include goatskin, pigskin, and chicken skin. ${ }^{17}$ Although they provide realistic skin experience, termed as "high fidelity," the use of these is marred by need for a special wet laboratory for practice and proper waste disposal management. Ethnic and cultural issues may also inhibit the use of these among learners. Commercially available skin simulation models have been found to be expensive. They cannot be recommended for routine and repeated practice by residents, although these provide the best models in a workshop setting, where participants may bear the expenses to some extent through registration fees. Foambased models not unlike ours have been described in literature for suturing practice by surgical trainees, however their use as simulation model for geometrical cutaneous flaps has not been described earlier. ${ }^{18,19}$

We have tried to utilize "the best out of waste" from the hospital-based available dressing material either nearing or postclinical use expiry dates, such as the bilayer foam-based adhesive dressing material, as a skin simulation model, for the practice of suturing and flap procedures. The tensile strength and acceptable pliability of the material make it easy to replicate many cutaneous flaps. Although the participants felt a lack of haptic feedback, and the pliability was not as good as normal skin, yet sixty percent of the participants were satisfied during use. It is available in two sizes $(10 \mathrm{~cm}$ $\times 10 \mathrm{~cm}$ and $15 \mathrm{~cm} \times 10 \mathrm{~cm}$ ), so small flaps, as well as larger rotation and transposition flaps, could be demonstrated to learners. The outer layer's texture mimics natural skin; hence, it was suitable to practice specialized suturing techniques like purse-string closure, subcuticular stitches, and Gilles A stitch. The adhesive portion of the model helped fix the model to a firm base and mimic fixed zones and boundaries of the face. This made it easier to demonstrate the limits of flap boundaries and the formation of dog ears during flap movements. Although we have used some of the old stock from the hospital pharmacy, the price of each adhesive simulation model is in the range of Rs 300 (4 USD) to Rs 
600 (8 USD) and available easily compared with commercial simulation models, which may cost around Rs 2000 (30 USD) to Rs 7000 (900 USD) per piece and are also not readily available locally. Obtaining regular supply of this material may be difficult for routine use. However, these can be procured directly from the manufacturer and utilized for flap training workshop sessions at periodic intervals. One way to address the regular supply of high-fidelity simulation models in a cost-effective manner, particularly in teaching institutes, is the possibility of in-hospital fabrication of simulation models, according to user needs. ${ }^{20}$ Till such systems are in place, we believe our low-cost, moderate-fidelity model may address the needs of plastic surgery trainees.

\section{Conclusions}

Adhesive bilayer polyurethane foam can be used as a novel cutaneous skin flap simulation model for understanding the biomechanics of skin flaps and cutaneous flap practice. This model is easily available and provides occasions for departments to institute competency-based training in their facial plastic surgery curriculum and allows plastic surgical trainees to improve their surgical skills.

\section{Source(s) of Support}

None.

\section{Conflicts of Interests \\ No conflicts of interests.}

\section{References}

1 Kotsis SV, Chung KC. Application of the "see one, do one, teach one" concept in surgical training. Plast Reconstr Surg 2013;131 (05):1194-1201

2 Thomson JE, Poudrier G, Stranix JT, Motosko CC, Hazen A. Current status of simulation training in plastic surgery residency programs: a review. Arch Plast Surg 2018;45(05):395-402

3 Soanes C, Stevenson A, eds. The Oxford Dictionary of English. Revised Edition. Oxford, UK: Oxford University Press; 2005

4 Nguyen VT, Losee JE. Time- versus competency-based residency training. Plast Reconstr Surg 2016;138(02):527-531
5 Motola I, Devine LA, Chung HS, Sullivan JE, Issenberg SB. Simulation in healthcare education: a best evidence practical guide. AMEE Guide No. 82. Med Teach 2013;35(10):e1511-e1530

6 Shah N, Desai C, Jorwekar G, Badyal D, Singh T. Competency-based medical education: An overview and application in pharmacology. Indian J Pharmacol 2016;48(Suppl 1):S5-S9

7 Hopmans CJ, den Hoed PT, Wallenburg I, et al. Surgeons' attitude toward a competency-based training and assessment program: results of a multicenter survey. J Surg Educ 2013;70(05):647-654

8 Gibson T, Kenedi RM. Biomechanical properties of skin. Surg Clin North Am 1967;47(02):279-294

9 Ericsson KA. Deliberate practice and the acquisition and maintenance of expert performance in medicine and related domains. Acad Med 2004;79(10, Suppl)S70-S81

10 Rosen JM, Long SA, McGrath DM, Greer SE. Simulation in plastic surgery training and education: the path forward. Plast Reconstr Surg 2009;123(02):729-738

11 Mitchell NM, Cutting CB, King TW, Oliker A, Sifakis ED. A real-time local flaps surgical simulator based on advances in computational algorithms for finite element models. Plast Reconstr Surg 2016; 137(02):445e-452e

12 Gupta S, Mohapatra DP, Chittoria RK, et al. Innovative use of abdominoplasty specimen. J Cutan Aesthet Surg 2018;11(02): 88-90

13 Khunger N, Kathuria S. Mastering surgical skills through simulation-based learning: Practice makes one perfect. J Cutan Aesthet Surg 2016;9(01):27-31

14 Delletec Surgical Procedure Simulators (Home page on the internet). Accessed January 25, 2021 at: http://www.delletec.com/ Skin\%20Closure\%202.htm

15 Erler-Zimmer Simulators (Home page on the internet). Accessed January 25, 2021 at: https://www.erler-zimmer.de/shop/en/medical-simulators/skin-suture/

16 Reddy R, Iyer S, Pillay M, Thankappan K, Ramu J. Soft embalming of cadavers for training purposes: optimising for long-term use in tropical weather. Indian J Plast Surg 2017;50(01):29-34

17 Denadai R, Toledo AP, Martinhão Souto LR. Basic plastic surgery skills training program on inanimate bench models during medical graduation. Plast Surg Int 2012;2012:651863

18 Olson J, Kalina C, Berg D. Foam dressing as a suturing model. Dermatol Surg 2013;39(06):952-953

19 Yag-Howard C. Making and using a mouse pad model of skin to practice suturing techniques. Dermatol Surg 2013;39(12): 1947-1949

20 Williams TP, Snyder CL, Hancock KJ, et al. Development of a lowcost, high-fidelity skin model for suturing. J Surg Res 2020; 256:618-622 